All letters are subject to editing and may be shortened. General letters can be sent to bjgpdisciarcgp.org.uk (please include your postal address for publication), and letters responding directly to BJGP articles can be submitted online via eLetters. We regret we cannot notify authors regarding publication.

For submission instructions visit: bjgp.org/letters

\section{Information flow to enable integrated health care: integration or interoperability}

It is undoubtedly true that digital systems are a key enabler of the transformation that is needed in the NHS if we are to provide safe, high-quality, affordable care for all our patients now and in the future.

But standards for care records that ensure that the right information is captured consistently is fundamental to enabling clinicians and professionals to exchange information digitally. This is why the role of the Professional Record Standards Body (PRSB), which I chair, is so important.

We need to get the systems right and this means designing them with clinical need in mind. We also need to ensure that clinicians and professionals adopt standards as fundamental to the way they record and use information to improve patient care. Last week's report on medications errors, published by the Department of Health, reinforces this point.?

At PRSB we recently visited secondary care providers to determine factors contributing to successful digital transformation where information flows across a local health economy. With one voice they said involving local GPs was critical. PRSB has made a series of GP videos about the importance of information sharing after discharge from hospital, which can be viewed at https://theprsb.org/ aboutus/videos-2/.

Maureen Baker,

Chair, Professional Record Standards

Body, London.

Email: maureen.bakeranhs.net

\section{REFERENCES}

1. Meaker R, Bhandal S, Roberts CM. Information flow to enable integrated health care: integration or interoperability. Br J Gen Pract 2018; DOI: https://doi.org/10.3399/bjgp18X694889.

2. Department of Health and Social Care. The Report of the Short Life Working Group on reducing medication-related harm. London: DH, 2018. https://uww.gov.uk/government/publications/ medication-errors-short-life-working-group-report laccessed 9 May 2018).
DOI: https://doi.org/10.3399/bjgp18X695897

\section{Making technology- enabled health care work in general practice}

As researchers working in the field of digital technologies in general practice, we did not recognise the landscape described in this editorial. ${ }^{1}$ Lumping together approaches to healthcare delivery on the basis of them having the common element of being a technology implies an assumption that their effectiveness lies with the technology, which evidence indicates is not the case.

Most worrying is the claim that it makes sense to get on with it and transform our conventional face-to-face delivery of care in general practice to modes of TECS that meet patients' needs and preferences as well as being more effective and productive for general practice teams - mirroring how people have converted to using technology in their everyday lives'. Evidence from research shows that in fact technologymediated consultations may lead to more work for GPs, and are not necessarily preferred by patients. ${ }^{2-7}$ For several types of technology-mediated interactions there is not enough high-quality evidence to be able to claim a transformative impact. 8,9

There is a widely held perception that, when it comes to technology, evidence is unimportant and an assumption that all consequences of use are positive, in a way that would be considered completely unacceptable for other interventions such as pharmaceuticals. Deciding to proceed with something that does not have an evidence base, or goes against the evidence base, is irresponsible and does not represent good practice or commissioning. Sadly, it is commonplace.

We urge those interested in using or commissioning technological approaches to healthcare delivery in their own practice to consider each technology type on its own merits, with reference to the (growing) research evidence base for their use.
Helen Atherton,

Assistant Professor of Primary Care Research, Unit of Academic Primary Care, Warwick Medical School, Coventry. Email: h.athertonawarwick.ac.uk

Brian McKinstry,

Professor of Primary Care eHealth and GP. University of Edinburgh, Edinburgh.

\section{REFERENCES}

1. Chambers R, Schmid M. Making technologyenabled health care work in general practice. $\mathrm{Br}$ J Gen Pract 2018; DOI: https://doi.org/10.3399/ bjgp18X694877.

2. Atherton $\mathrm{H}$, Brant $\mathrm{H}$, Ziebland S, et al. Alternatives to the face-to-face consultation in general practice: focused ethnographic case study. $\mathrm{Br}$ J Gen Pract 2018; DOI: https://doi.org/10.3399/ bjgp18X694853.

3. Edwards HB, Marques E, Hollingworth W, et al. Use of a primary care online consultation system, by whom, when and why: evaluation of a pilot observational study in 36 general practices in South West England. BMJ Open 2017; 7(11): e016901.

4. Banks J, Farr M, Salisbury C, et al. Use of an electronic consultation system in primary care: a qualitative interview study. Br J Gen Pract 2018; DOI: https://doi.org/10.3399/bjgp17X693509.

5. Leahy D, Lyons A, Dahm M, et al. Use of text messaging in general practice: a mixed methods investigation on GPs' and patients' views. $\mathrm{Br} J$ Gen Pract 2017; DOI: https://doi.org/10.3399/ bjgp17X693065

6. Pinnock $\mathrm{H}$, Hanley J, McCloughan L, et al. Effectiveness of telemonitoring integrated into existing clinical services on hospital admission for exacerbation of chronic obstructive pulmonary disease: researcher blind, multicentre, randomised controlled trial. BMJ 2013; 347: $f 6070$.

7. Stoddart A, Hanley J, Wild S, et al. Telemonitoringbased service redesign for the management of uncontrolled hypertension (HITS): cost and costeffectiveness analysis of a randomised controlled trial. BMJ Open 2013; 3(5): e002681.

8. Armoiry X, Sturt J, Phelps EE, et al. Digital clinical communication for families and caregivers of children or young people with short- or long-term conditions: rapid review. J Med Internet Res 2018; 20(1): e5

9. Fatehi F, Armfield NR, Dimitrijevic M, Gray LC. Technical aspects of clinical videoconferencing a large scale review of the literature. J Telemed Telecare 2015; 21(3): 160-166.

DOI: https://doi.org/10.3399/bjgp18X695909 